\title{
Operational Impact of the Baseline Integrated Arrival, Departure, and Surface System Field Demonstration
}

\author{
Shivanjli Sharma \\ Ames Research Center \\ NASA \\ Moffett Field, CA, USA \\ shivanjli.sharma@nasa.gov
}

\author{
Al Capps \\ North Texas Research Station \\ NASA \\ Fort Worth, TX, USA \\ al.capps@nasa.gov
}

\author{
Shawn Engelland \\ North Texas Research Station \\ NASA \\ Fort Worth, TX, USA \\ shawn.engelland@nasa.gov
}

\author{
Yoon Jung \\ Ames Research Center \\ NASA \\ Moffett Field, CA, USA \\ yoon.c.jung@nasa.gov
}

\begin{abstract}
To address the Integrated Arrival, Departure, and Surface (IADS) challenge, NASA is developing and demonstrating trajectory-based departure automation under a collaborative effort with the FAA and industry known as Airspace Technology Demonstration 2 (ATD-2). ATD-2 builds upon and integrates previous NASA research capabilities that include the Spot and Runway Departure Advisor (SARDA), the Precision Departure Release Capability (PDRC), and the Terminal Sequencing and Spacing (TSAS) capability. The ATD-2 field demonstration is organized into three phases. Phase I illustrates a Baseline IADS demonstration and includes all components of ATD-2 running in operational environments. Subsequent phases will fuse together strategic scheduling components as well as take into account metroplex considerations.
\end{abstract}

This paper describes the baseline IADS system that was deployed at the end of 2017 and is continuing to run as part of the ATD-2 demonstration taking place at Charlotte-Douglas International Airport (CLT). The primary areas of deployment and system use are in the CLT Air Traffic Control Tower, CLT TRACON, CLT American Airlines ramp tower, Washington Center facility and American Airlines Integration Operations Center (IOC). In addition to describing the functions and capabilities that are part of the baseline IADS system, this paper also provides metrics regarding operational use as well as initial benefits metrics. Benefit metrics continue to be collected and aggregated across the areas of system delay, throughput, taxi time, fuel burn savings, and emissions savings. Furthermore, benefits as a result of common awareness of delays and the impact of takeoff and departure restrictions stemming from traffic flow management initiatives are described. The overall benefit of improved predictability and efficiency as a result of the baseline IADS system demonstration is also discussed.

Keywords-air traffic management, field demonstration, integrated arrival, departure, surface system, operational benefits analysis

\section{INTRODUCTION}

The NASA Airspace Technology Demonstration 2 (ATD-2) project is a series of field demonstrations that evaluates the benefits of the wholistic consideration of integrated arrival, departure and surface (IADS) traffic flows while introducing new technologies and procedures into its collaborative operational environment. NASA, the Federal Aviation Administration (FAA), the air traffic controllers and airline industry partners successfully deployed the Phase 1 Baseline Integrated Arrival, Departure, Surface (IADS) traffic management capability of NASA's Airspace Technology Demonstration 2 (ATD-2) system in late 2017 at CharlotteDouglas International Airport (CLT) in Charlotte, NC. The primary goal of ATD-2 is to improve the predictability and the operational efficiency of the air traffic system in metroplex environments, through the enhancement, development, and integration of the nation's most advanced and sophisticated arrival, departure, and surface prediction, scheduling, and management systems.

The results of the field demonstration target technology are provided to relevant parties in the National Airspace System (NAS), including the FAA's Next Generation Air Transportation System (NextGen) program [1], airline operators and the broader aviation community. The field demonstration responds to a NextGen Advisory Committee (NAC) recommendation [2] which suggests evaluating the integration of departure metering that reflects the FAA's Surface Collaborative Decision Making (CDM) Concept of Operations [3].

ATD-2 is accomplished by executing three major phases of activity over a three-year period. NASA, together with its FAA and industry partners, selected CLT as the site for initial field demonstration. The first phase of activity began on September 29th, 2017 and is focused on establishing the baseline IADS capability upon which increasing levels of capability are being added in an agile manner. This paper describes the baseline IADS system that was deployed at the end of 2017 and is 
continuing to run as part of the ATD-2 demonstration taking place at Charlotte-Douglas International Airport (CLT).

The paper first provides background on the ATD-2 concept and IADS capabilities that are currently being demonstrated in the field environment. The paper then describes results of the first phase IADS baseline system that continues to run in CLT Air Traffic Control Tower, CLT Terminal Radar Approach Control (TRACON), CLT American Airlines ramp tower, Washington Air Traffic Control Center (ARTCC or Center) and American Airlines Integration Operations Center (IOC). The initial benefits of each capability will be discussed in this paper as well as key lessons learned.

\section{BACKGROUND}

\section{A. ATD-2 Background}

NASA's research activities in the IADS domain include the Spot and Runway Departure Advisor (SARDA) [5-12] the Precision Departure Release Capability (PDRC) [13-20] and the Terminal Sequencing and Spacing (TSAS) [5] research projects. Early SARDA research focused on movement area traffic advisories for the Airport Traffic Control Tower (ATCT, or Tower) personnel. Later SARDA research, in collaboration with American Airlines (AAL), focused on non-movement (i.e., ramp) traffic advisories for ramp control (i.e., ramp controllers and ramp managers). The PDRC research activity focused on using predicted takeoff times and departure runway assignments from a trajectory-based surface system to improve overhead stream insertion calculations performed by Time Based Flow Management (TBFM) departure scheduling functions. PDRC research was transitioned to the FAA in 2013 for use in the TBFM and Terminal Flight Data Management (TFDM) programs. TSAS research is the combination of TBFM for terminal area scheduling and Controller Managed Spacing (CMS) tools for TRACON controllers. The TSAS research was successfully transferred to the FAA in 2014 for use in TBFM.

The FAA NextGen plans call for the NAS IADS capabilities to be implemented via a trio of decision support systems (DSS) [21]. Traffic Flow Management (TFMS), TBFM and TFDM are the primary systems in this group that are commonly called the "3Ts." Integration of the 3T systems is a major emphasis for the FAA, and it is central to the ATD-2 concept and field demonstration effort. The reader is referred to the ATD-2 Technology Description Document (TDD) for more information regarding the $3 \mathrm{~T}$ integration effort. [11]

ATD-2 was formulated as a subproject in 2015 as a part of NASA's Airspace Operations and Safety Program (AOSP) within the Aeronautics Research Mission Directorate. The ATD-2 research and development objectives were developed through extensive engagement with NAS stakeholders to understand the existing shortfalls in arrival, departure, and surface operations, and the perceived benefits of an IADS solution. [7] At the same time, the FAA committed to establishing an initial airport surface departure metering capability consistent with its Surface CDM concept of operations. The ATD-2 subproject, as well as the NAC and the FAA, evaluated candidate field demonstration sites for the IADS capability, and CLT was selected by the FAA in 2015.
Figure 1 illustrates the operational environment for the IADS system in the Phase 1 Baseline IADS demonstration. The upper portion of the figure depicts en route airspace controlled by the Centers. The dashed line represents the boundary between the Home Center and the adjacent Center. The cylinder in the lower portion of the figure represents terminal airspace controlled by the TRACON facility. The Tower manages surface traffic in the active movement area (AMA), and the AAL-operated Ramp manages traffic in the CLT ramp area.

The operational environment graphic shows aircraft trajectories departing from (blue) and arriving to (red) the terminal airspace. The colored ovals illustrate some of the meter points at which air traffic is scheduled, either by automated systems or manual procedures. Red ovals are arrival meter points. Blue ovals are departure meter points. Yellow ovals are surface meter points. The takeoff point, represented by a half yellow/half blue oval, represents an important control point for the IADS concept, as they are the interface points between surface and airspace scheduling. The funnel located at the top right of Fig. 1 represents a downstream demand/capacity imbalance that results in departure restrictions on the local terminal airspace.

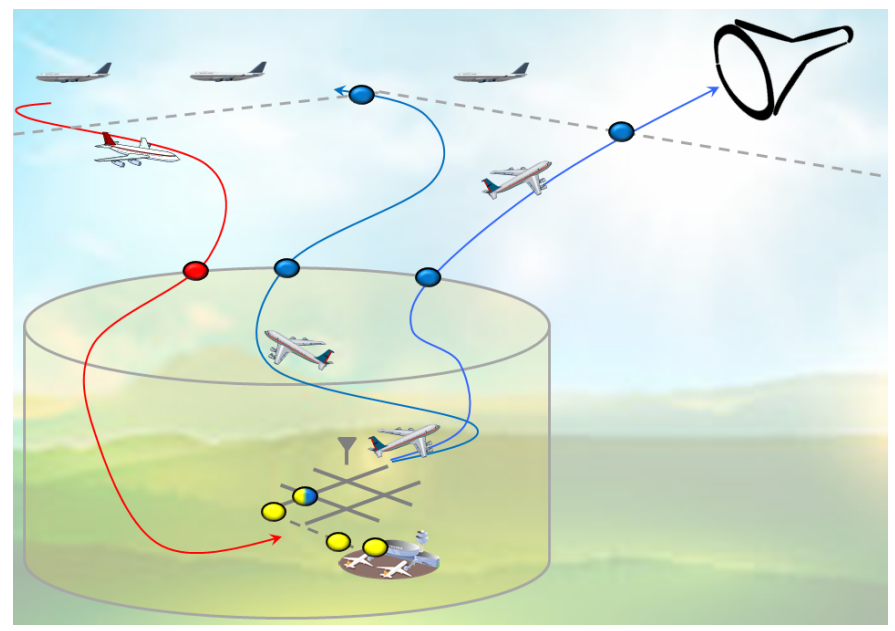

Fig. 1. Airspace Technology 2 (ATD-2) concept graphic.

\section{B. CLT Surface and Airspace Operations}

The following section gives an overview of the CLT surface and airport operations to provide context for the manner in which the benefits metrics were assessed in Phase I of ATD-2, as well as some of the operational metrics shown in later sections.

The CLT Airport Activity Report of January 2017 enumerates that the CLT Tower controls around 1,400 operations per day. The Airport Council International Report shows CLT as ranked seventh in movements worldwide for 2016. The total count of CLT TRACON operations on a visual meteorological condition (VMC) day is around 1,500 daily. Thus, the vast majority of traffic managed by the TRACON is destined for, or departing from, CLT.

The distribution of CLT traffic operations by carrier, based on data collected for the same period, shows that American Airlines (AAL) and regional air carriers operate nearly $85 \%$ of the flights into and out of CLT. Besides the main terminal for 
commercial and regional airlines, CLT also is responsible for the Wilson Air Center (a fixed base operator that provides services to corporate and private flights), the North Carolina Army Guard, and the North Carolina Air National Guard. These general aviation and military flights comprise approximately $4 \%$ of CLT traffic.

Situated between the Washington DC metroplex (300 nm away) and the Hartsfield-Jackson Atlanta International Airport ( $200 \mathrm{~nm}$ away), CLT underlies one of the busiest air traffic corridors on the east coast. As shown in Fig. 2, CLT is located in the northeast corner of Atlanta Center (ZTL) airspace, approximately 18 miles from the ZTL boundary with Washington Center (ZDC) on the east side and sits on the border of the Jacksonville Center (ZJX) on the south side. This location significantly influences operations at CLT and makes CLT the subject of frequent traffic flow management constraints.

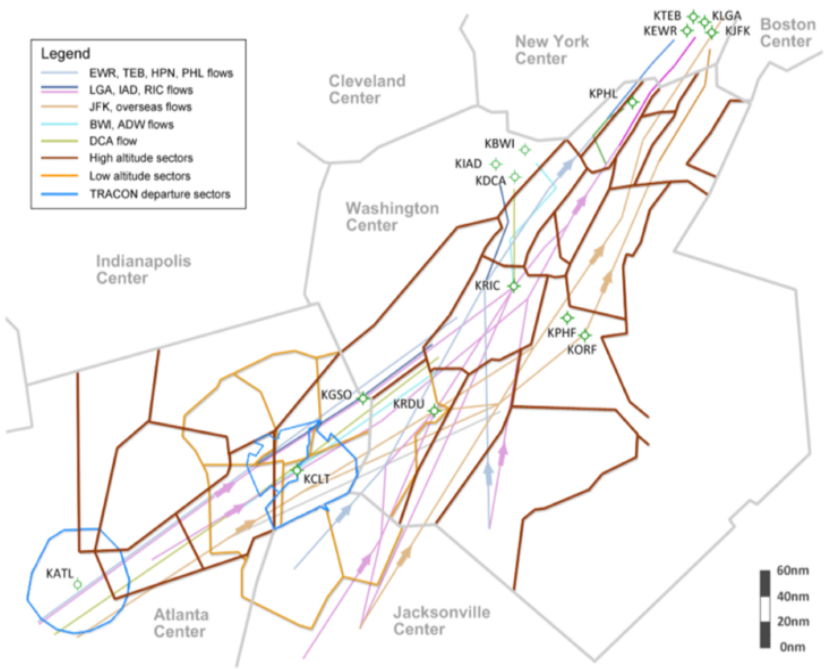

Fig. 2. The CLT airport location in ZTL, adjacent Centers, and jetways showing transiting traffic near CLT.

CLT has three north/south parallel runways (18L/36R, $18 \mathrm{C} / 36 \mathrm{C}$, and $18 \mathrm{R} / 36 \mathrm{~L})$ that support simultaneous independent instrument approaches, and a fourth diagonal runway $(5 / 23)$ that intersects runway $18 \mathrm{~L} / 36 \mathrm{R}$. Runway $18 \mathrm{R} / 36 \mathrm{~L}$ was commissioned in 2010 and is primarily used for arrivals. Runway $5 / 23$ is used for arrivals in South Flow Configuration and is used as a taxiway during North Flow Configuration. Runway $18 \mathrm{C} / 36 \mathrm{C}$ is a mixed-use runway, whereas runway $18 \mathrm{~L} / 36 \mathrm{R}$ is used primarily for departures. The current operations capacity rate range in visual conditions is 176-182 operations per hour. CLT operates in either North or South Flow Configuration depending on the primary traffic flow direction. When operating in South Flow Configuration, converging runway operations are normally used.

Taxi in and out times vary significantly across the three configurations discussed: North Flow Configuration, South Simultaneous Configuration, and South Converging Configuration. Fig. 3. illustrates a bubble plot indicating the taxi in and out times across the ramp and AMA in CLT. The bubble plot is designed such that the center of the circle represents the mean of the set of data. The area or size of the circle is based on the variance of the data set, meaning the larger the circle the greater the distribution or standard deviation across the data aggregated. As seen in Fig. 3., the mean taxi out time in the AMA when in North Flow Configuration is 11.67 min compared to $9.25 \mathrm{~min}$ in South Simultaneous Configuration. Conversely, the taxi out time in the ramp is 4.21 min when in North Flow Configuration compared to $10.71 \mathrm{~min}$ in South Simultaneous Configuration.

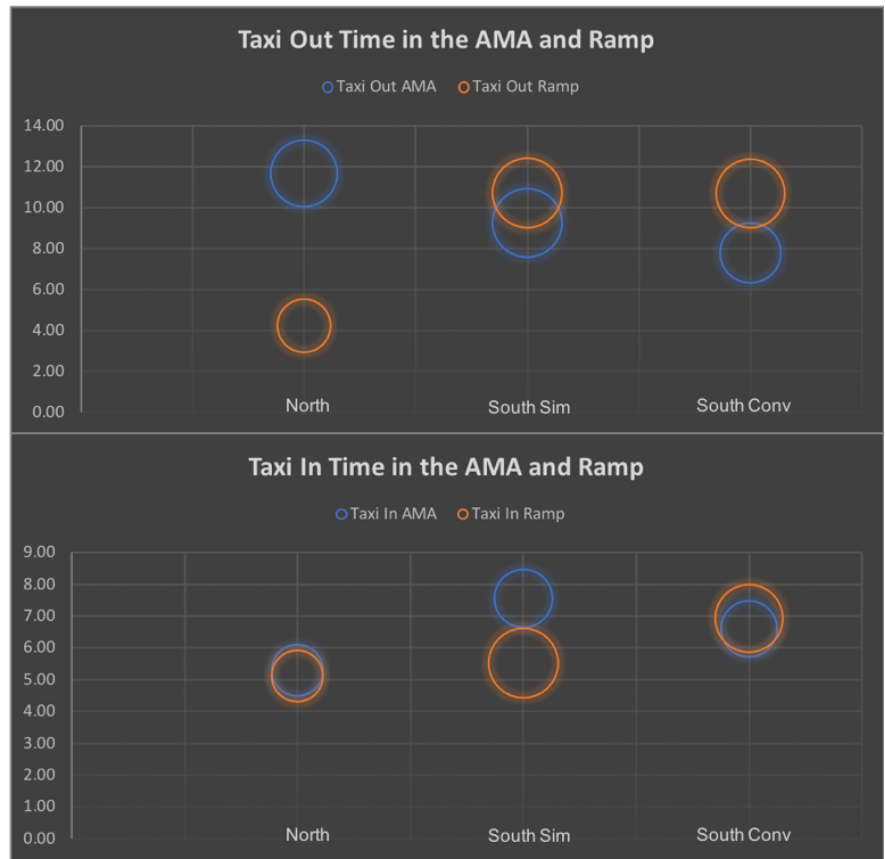

Fig. 3. Variations in taxi in and out times in the ramp and AMA across different airport configurations.

Given the above traffic conditions/compositions, the data analysis conducted to derive benefits metrics was highly dependent on airport configuration. The variations in taxi time across the various configurations, as seen in Fig. 3., led the analysis to focus on excess taxi time as a metric to gauge the impact of the IADS capabilities in CLT. Excess taxi time refers to a calculation that reduces the impact of variations due to configuration by considering the amount of taxi time that is measured in excess of unimpeded taxi time as calculated by the IADS surface model, which is detailed in Section III.

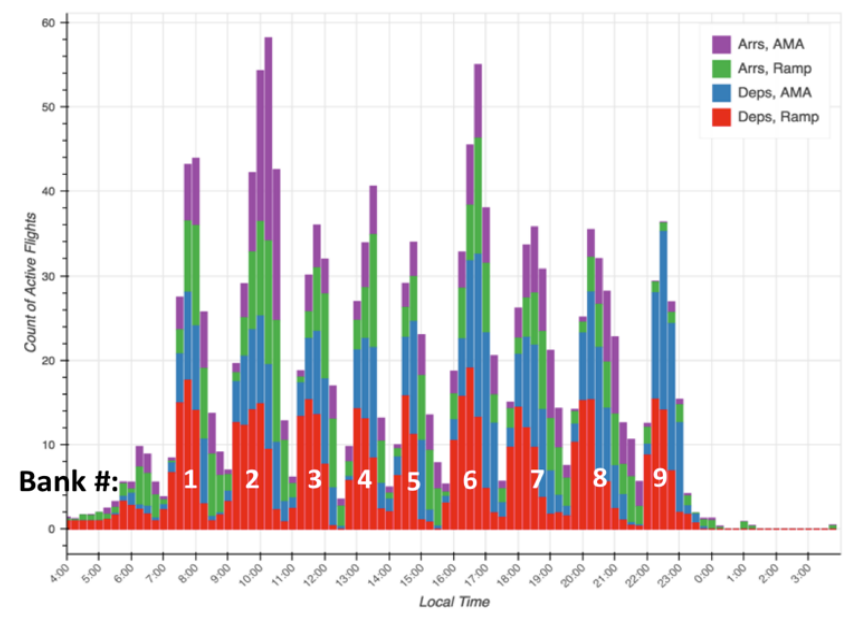

Fig. 4. CLT airport surface counts illustrating departure and arrival banks on a given day. 
In addition to comparing data across similar configurations, metrics in this paper are also grouped across banks. A bank is defined as a block of departures and arrivals scheduled at fairly consistent times. Fig. 4. Illustrates the manner in which CLT operates with a banked schedule by showing airport surface counts across four categories: number of arrivals in the AMA, number of arrivals in the ramp, number of departures in the AMA, and the number of departures in the ramp. The counts of arrivals and departures are shown in fifteen-minute window increments. Fig. 4. shows CLT operations across nine distinct banks with groups of departures and arrivals consistently in a given time interval. The earliest group of surface counts shown in the graph consists primarily of arrivals and thus is not considered the first bank. Bank 2 and 3 (centered around 8am and 10 am respectively) are banks that will be referenced most frequently as these are the banks that surface metering has been utilized as part of daily operations. Bank 2 typically has an average of 76.7 departures and 77.8 arrivals, whereas bank 3 typically has an average of 76 departures and 53 arrivals. These two banks represent higher density blocks of arrivals and departures relative to the other banks throughout the day.

Operational data and benefits metrics outlined in upcoming sections will be often grouped by bank to allow for effective comparisons. The interplay between timings of departure and arrival banks as well as the density have an impact on many metrics, therefore comparing across like banks provides a more accurate assessment of the impact of the IADS system in CLT.

\section{Surface CDM and TFDM Requirements}

Both the FAA's Surface CDM Concept of Operations and the TFDM Program have a large role in the development of ATD-2.[1,13] TFDM is a new decision support system for airport surface management and ATC tower functions and capabilities that will be implemented incrementally in a phased approach beginning in 2020. Electronic Flight Data will be one of the first technology components as part of the TFDM system.

One of the primary motivators for FAA/NASA collaboration on the ATD-2 field demonstration is reducing the risk for the TFDM implementation of the Surface CDM departure queue management. As part of this effort, the Surface CDM and TFDM requirements were reviewed and continue to play a role in the development of ATD-2 and future phases. In addition, the benefits metrics and lessons learned are a part of the technical transfer between NASA and the FAA. The technical transfer process is underway and will continue to occur across the three phases of ATD-2.

\section{IADS SYSTEM CAPABILITIES}

The Phase 1 Baseline IADS system provides a series of capabilities built upon core modeling and scheduling algorithms. The Phase I Baseline IADS system consists of the core Surface Predictive Engine upon which are layered capabilities of Data Exchange and Integration, Overhead Stream Insertion, and Collaborative Surface Metering. The core system is referred to as the Surface Predictive Engine and is based on generating an accurate surface model and associated schedule. The core system as well as its capabilities will be briefly discussed in this section. Detailed descriptions of these capabilities can be found in the ATD-2 Phase 1 Concept of Use document. [21]

One of the foundations of the IADS core capabilities is based on the ingestion of a set of disparate System Wide Information Management (SWIM) feeds from the FAA in combination with industry flight specific data streams. These data are resolved into a single globally unique flight identifier that is updated as additional information and is ingested into the IADS system. The mediation rules developed as part of the foundation of the IADS system represent a novel use of the input data as well as an example of how this single flight object can be utilized to provide the most accurate predictions of an aircraft's ON and OFF time relative to its position on the airport surface. The architecture designed to integrate these data feeds and mediation rules are detailed in the ATD-2 Phase 1 Technology Description Document. [22]

\section{A. Surface Predictive Engine}

The surface predictive engine consists of the surface modeler and surface scheduler. Once the data feeds discussed above, as well as key inputs from operational users, are fused together, then this consistent input is provided to the Surface Modeler. The surface model adds key trajectory-based calculations based on events and provides unobstructed taxi time estimates based on its knowledge of a flight's current and proposed location (e.g., spot through departure runway). The surface model updates if a flight deviates from its expected trajectory and utilizes surveillance data to update start time and position of the flight. The IADS Surface Modeler also updates the state of each flight and predicts the gate, spot, runway, and taxi route.

Ultimately, the Surface Modeler's function is to predict unobstructed trajectories of aircraft on the surface and generate estimated takeoff times for the surface scheduler to use in computing target times for takeoff, spot release, and gate pushback. The Surface Modeler relies on accurate gate departure time estimates based on Earliest Off-block Times (EOBTs) and other flight readiness status, such as pilot call-in, to predict takeoff times. The Surface Modeler also receives ON time estimates and landing runway assignments for the arrival aircraft to use for trajectory prediction and scheduling.

The IADS Surface Scheduler generates Target Takeoff Times (TTOTs) for departure flights based on taxi routes and times predicted by the Surface Modeler, with appropriate constraints. Since the Surface Scheduler generates TTOTs based on a flight's gate departure time, it is important to have accurate EOBTs in order to predict accurate TTOTs. In reality, however, not every flight's EOBT is of high quality. In order to allocate runway times equitably and fairly in the tactical timeframe, the IADS Surface Scheduler handles flights differently depending on the demonstrated accuracy of their EOBTs. Once TTOTs have been calculated, then Target Movement Area entry Times (TMATs) and Target Off-block Times (TOBTs), are calculated using a delay propagation formula. Detailed descriptions of the surface scheduler and the rules applied can be found in the ATD2 Phase 1 Technology Description Document. [22]

\section{B. Data Exchange and Integration}

The surface model and schedule data calculated by the surface predictive engine are augmented and supplemented by 
the foundational capability of data exchange and integration. The Phase 1 Baseline system enables multiple users in operational areas to interact via a single IADS system through the automation. Users share the same data, exchange information, and make decisions collaboratively. Through this capability, users working at different facilities, such as the Tower and the Ramp, have common situation awareness, thus enabling reduced voice communications in daily operations.

NASA researchers met with ATCT controllers from CLT, AAL ramp controllers, and ZDC controllers across a series of fifteen collaborative meetings in the last year at CLT in order to define information required for data exchange. Through these discussions, data exchange and integration items were identified and implemented as inputs to the user interfaces located across the operational areas. The following list provides an example of the type of information identified and incorporated in the IADS system:

- Runway utilization

- Runway assignments

- Handling of Miles in Trail (MIT) restrictions

- Approval Requests for Call for Release (APREQ)/Call for Release (CFR)

- Ground stops

- Runway closures

- Departure fix closures

- Flight cancellations

- Gate conflicts

- Ramp closures

- Manual updates/corrections of flights

- Long on Board (LOB) common awareness

The Tower TMC can input runway utilization plans or Traffic Management Initiative (TMI) restrictions (e.g., MIT, APREQ/CFR, and Ground Stop) through the user interfaces that are available to TMCs in the Tower and TRACON. Ramp Control can also input their decisions or requests (e.g., runway assignment, flight cancellation and ramp closure) through their user interfaces in the AAL Control Center at CLT. These inputs are then shared with the Tower and displayed on the clients. The benefits of the real time ATD-2 tool is that it not only has access to the incoming data sources to the system, but it is also able to leverage the data exchange elements listed above, thus providing a full operational view of the airport at any given time.

\section{Overhead Stream Insertion}

Once a common operational view of the airport surface has been established through data exchange and integration, additional capabilities were added to provide the Phase 1 Baseline IADS functionality. Overhead stream insertion refers to the capability of enabling electronic tactical departure scheduling. This capability facilitates non-verbal coordination of the APREQ/CFR process between CLT Tower and the ZDC Center. This capability leverages FAA investments in the TBFM's Integrated Departure and Arrival Control (IDAC) capability. Overhead stream insertion is integrated with TBFM/IDAC to request a release time into the overhead stream of traffic in ZDC. The IADS system user interface in CLT tower emulates the TBFM/IDAC interface used to select a slot at the meter point and receive the corresponding release time without verbal communication with the Center TMC.

The IADS technology enabling this capability is the accurate prediction of the Earliest Feasible Takeoff Time (EFTT) and the generation of the target pushback time by the Surface Scheduler to meet the Controlled Take Off Time (CTOT). This enables holding of the aircraft at the gate for the right amount of time. The IADS system user interface sends a notification to the Tower TMC to facilitate earlier APREQ/CFR coordination while the aircraft is still at the gate. The release time is automatically shared with the Ramp controllers. An APREQ/CFR flight is marked on its flight strip, and the release time and the corresponding target pushback time are displayed on the IADS system user interface for ramp controllers as soon as the times are available. [23]

\section{Collaborative Surface Metering}

The concept of collaborative surface metering entails utilizing small gate hold metering advisories to shift delay from aircraft waiting in a queue at the runway back to the gate. Metering advisories provide the control that adjusts demand to meet capacity. In Phase 1 Baseline IADS operations in CLT, the tactical metering on/off decision has been made as a collaborative decision between the Ramp Manager and Tower TMC. When metering is on, TOBTs are converted into gatehold or push advisories for the ramp controller. The TMATs are also provided to the ramp controller. Through the scheduling process, flights with CTOTs (e.g., APREQ/CFR, EDCT) will not be subject to gate-hold metering, in order to avoid potential double delay due to both metering and TMI restrictions. Flight operators can also designate certain flights, such as heavy jets, as exempt from metering holds. This can be done through either the adaptation or a manual entry by the Ramp using the IADS system user interface.

The Phase 1 Baseline IADS Demonstration at CLT has focused on tactical metering control on the pushback advisory (i.e., TOBT). However, it is recognized that not all airports have a mechanism/person to receive pushback advisories or to provide pushback instructions to the flight deck, hence at those airports surface metering must rely on conformance to TMATs. Principles of surface metering can be more generally applied to other airports in the NAS to adjust demand via spot-release times (TMATs). The Phase 2 IADS system demonstration, scheduled to commence at the end of 2018, will explore strategic surface metering implementation similar to capabilities laid out by SCDM. [3]

\section{Phase 1 Baseline IADS System Operational USE AND INITIAL BENEFTIS DATA}

The Phase 1 Baseline IADS system has been used in operations since the start of the field demonstration at the end of September 2017. The system's capabilities were deployed in a phased approach with the demonstration commencing with data exchange and integration. The overhead stream insertion capability between CLT Tower and ZDC commenced on November 1, 2017 and collaborative surface metering initialized on November 28, 2017. A phased approach allowed for users to gain familiarity with foundational capabilities before 
introducing new functions associated with electronic overhead stream insertion and surface metering.

The following section provides operational data from the Phase 1 Baseline IADS demonstration as well as initial benefits metrics. In addition to operational data and benefits metrics, key lessons learned from the demonstration are also introduced. The data provided in an initial view of benefits metrics and does not span the entire Phase 1 period of the ATD-2 Field Demonstration, therefore much of this information is construed as initial views of benefits that continue to be analyzed and assessed.

\section{A. Data Exchange and Integration - Operational Data}

The foundational capability of data exchange and integration enables shared situational awareness of the airport surface at any given time. User interfaces for the IADS system have been in operational use since the start of the Phase 1 Baseline demonstration, and were extensively evaluated in several human factor's assessments. In addition, key elements of data exchange continue to be refined through the agile software development process. Two of the key areas of improvement due to data exchange and integration are the use of EOBTs and the electronic sharing of key situational awareness elements described in Section II above.

The surface predictive engine and data exchange decisions are based on accurate gate departure time estimates provided as EOBTs. Accurate EOBT estimates allow for greater predictability in TTOT calculations and therefore greater accuracy in upstream times such as TMATs and TOBTs. In addition to system accuracy for surface metering to be effective, these EOBT predictions are also used for TMC planning, overhead stream insertion, and downstream system integration in the FAA's TFMS system. Fig. 5. illustrates improvement of EOBT times compared to legacy airline times. In the Phase 1 IADS Baseline demonstration, EOBT prediction accuracy has shown to be $40.9 \%$ more accurate than legacy airline times as provided in operator's latest gate time of departure (LGTD) when assessed 10 minutes prior to pushback. Accuracy was measured by comparing EOBTs and LGDTs to actual off block times (AOBT) as provided by ramp controllers via the ATD-2 user interfaces. As the amount of time relative to pushback increases, the EOBT accuracy degrades and at 25 minutes prior to pushback EOBT and legacy LGTD times are generally the same in terms of accuracy. In addition to EOBT accuracy, predictability of the times was also assessed. These data revealed that at 10 minutes prior to pushback, EOBTs had $17.6 \%$ more predictability compared to legacy off block estimates.

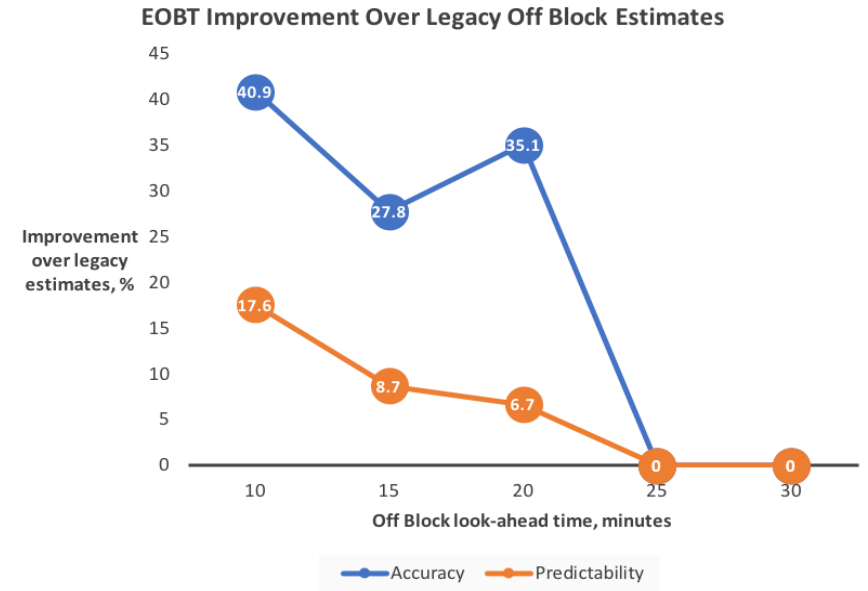

Fig. 5. Comparison of EOBT to legacy off block airline estimates in terms of accuracy and predictability.

Anecdotally, users in the field have reported a reduction in the number of phone calls given that TMCs in CLT Tower now have the ability to electronically communicate runway utilization information as well as departure fix closures, along with many other data exchange elements, to ramp controllers.

\section{B. Overhead Stream Insertion - Operational Data and Benefits}

Overhead stream insertion has been used almost every day since the capability was introduced on November of 2017. CLT has an average of 720 departures each day. Of those departures, 89 flights are subject to a TMI. Given that almost $12 \%$ of all flights are subject to an APREQ (or Call for Release), this capability has been effective on a number of fronts during the Phase 1 Baseline demonstration. This section will outline the operational use of this capability, fuel burn savings associated with this capability as a result of data exchange with the ramp, as well as delays savings in the NAS as a result of opportune renegotiation of APREQ slots that are now visible to TMCs utilizing the IADS system.

The Phase 1 demonstration established electronic overhead stream negotiation with ZDC as part of the capabilities of the baseline IADS system. Table 1 provides initial overhead stream operational data from November 1, 2017 to May 2018 and illustrates that on average 64 departures are subject to an APREQ each day. On average, $62 \%$ of those APREQ flights are through ZDC and thus can be electronically negotiated using the IADS system's capabilities. Thus far, of those flights that could be electronically negotiated through ZDC utilizing the IADS tools in CLT Tower, $85 \%$ were electronically negotiated to find a departure slot in the overhead stream. This percentage is likely to be affected by staffing considerations of TMCs in the Tower. There are periods of time during which slots cannot be electronically coordinated because of reduced staffing, thus reducing the number of flights that are negotiated using the IADS tools. 
TABLE I. OVERHEAD STREAM INSERTION OPERATIONAL DATA

\begin{tabular}{|l|c|}
\hline \multicolumn{1}{|c|}{$\begin{array}{c}\text { APREQ (Call for Release) } \\
\text { Operational Data }\end{array}$} & $\begin{array}{c}\text { Number of } \\
\text { Departures }\end{array}$ \\
\hline $\begin{array}{l}\text { Average Number of Departures } \\
\text { Subject to an APREQ/CFR }\end{array}$ & 64 \\
\hline $\begin{array}{l}\text { Average Number of APREQs to } \\
\text { ZTL }\end{array}$ & 24 \\
\hline $\begin{array}{l}\text { Average Number of APREQs to } \\
\text { ZDC }\end{array}$ & 40 \\
\hline $\begin{array}{l}\text { Average Number of APREQs to } \\
\text { ZDC Electronically Negotiated } \\
\text { with the IADS System }\end{array}$ & 34 \\
\hline
\end{tabular}

In addition to the overhead stream negotiation capability being used by CLT Tower TMCs, ramp controllers now have visibility into these negotiated APREQ times through the data exchange and integration capabilities. Procedurally, ramp controllers began a process in Phase 1 of ensuring that flights subject to an APREQ had a time negotiated prior to pushback. This procedural change of negotiating an APREQ at the gate, as well as visibility of the times, has resulted in initial benefits. As soon as a time is electronically negotiated or is available via SWIM (for ZTL flights), this APREQ time is then propagated to the ramp controller displays. Often times, the APREQ time is later than scheduled pushback time. The ramp controller now has sufficient information to determine if a flight can be held at the gate to meet its TMI. This ability to incur fuel savings by waiting at the gate rather than in a location on the ramp or AMA has been quantified. These fuel burn savings are separate from those associated with collaborative surface metering, which will be outlined in the next section. Due to the electronic overhead stream negotiation and data exchange and integration capabilities, 85,648 lbs of fuel have been saved from November of 2017 to May of 2018. The fuel burn savings estimate is based on a calculation that utilizes the time savings and an assumption of an all-engine taxi at idle thrust under standard atmospheric conditions. Furthermore, fuel savings estimates rely on data from the ICAO Databank, which provides fuel-flow rates per engine, mapped to a given aircraft type.

Along with fuel savings associated with negotiating for an overhead stream slot at the gate, time savings in the NAS have also been assessed given the use of the IADS tools and the ability to renegotiate for an earlier APREQ time. Once the Tower TMC has negotiated for a slot with ZDC, the IADS user interface provides an indication if a flight will be early, late, or on time for that TTOT using up-to-date surface model and schedule data. This indication paired with the ability to view available overhead stream slots on a single user interface allows the TMC the potential to renegotiate for an earlier overhead stream slot. Fig. 6. illustrates the number of times an APREQ time was negotiated and renegotiated for flights during the period of Dec 14, 2017 to Jan 13, 2017. The figure illustrates that during this time period there were 814 flights that were electronically negotiated between CLT and ZDC for an overhead stream slot, and of those flights, 19\% were renegotiated for another APREQ CTOT. These renegotiations often occur because the sequence of flights entering the AMA have a level of uncertainty that alter the taxi time of a flight to the runway.

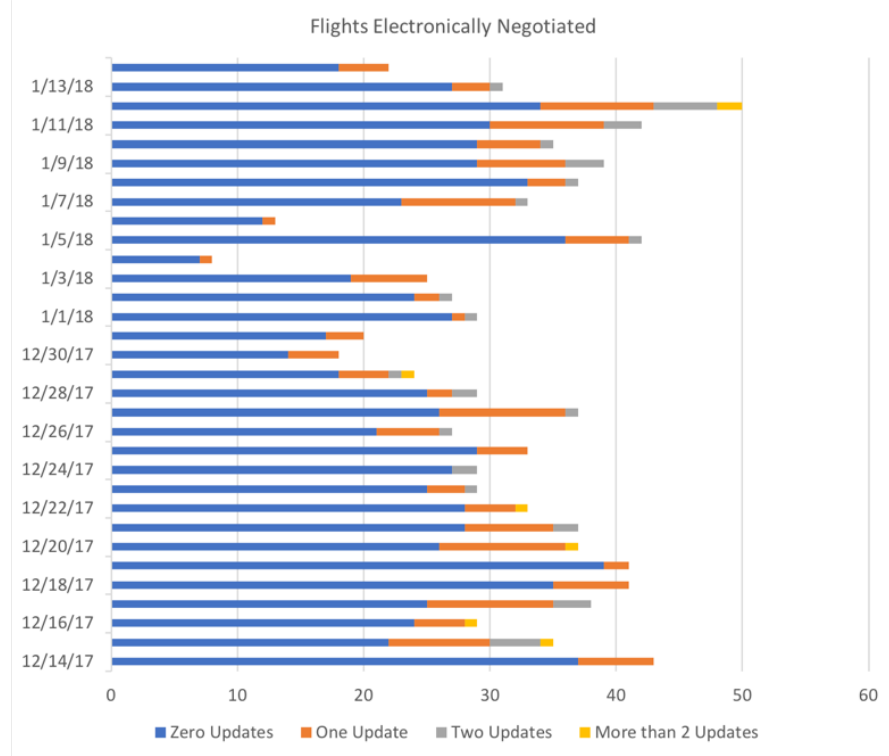

Fig. 6. Number of electronic overhead stream neogtiations and renegotiations.

The trend of renegotiation for earlier APREQ CTOTs was analyzed along with the associated overall NAS-wide time saving benefits. Fig. 7. illustrates both the number of minutes saved for each flight for each renegotiation of an earlier CTOT, as well as the aggregate number of hours saved from November 2017 to May 2018. The average delay savings across the flights that were renegotiated for an earlier APREQ overhead stream slot was 8.19 minutes. There is variance in the amount of delay savings in the data set with a mean of $6.96 \mathrm{~min}$ and a standard deviation of $7.07 \mathrm{~min}$. Much of this variance can be attributed to changing TMIs in the Northeast corridor due to weather disruptions and uncertainties associated with taxiing in a congested ramp area.

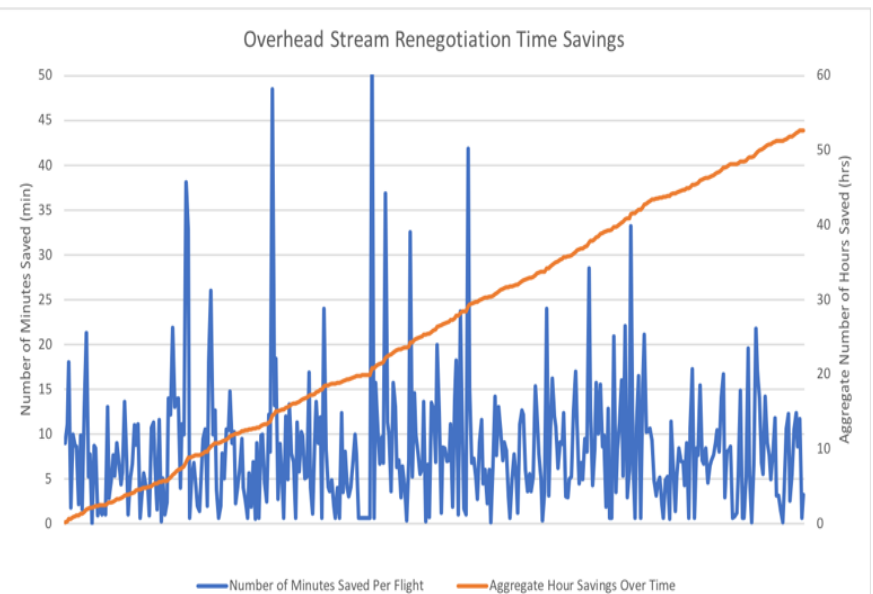

Fig. 7. Overhead stream renogiation time savings for individual aircraft in minutes and as an aggregate over time in hours.

Table II summarizes the overhead stream insertion renegotiation benefits. Initial analysis indicates that between November of 2017 and May of 2018, 386 flights have been renegotiated for an earlier APREQ time and that the total aggregate delay savings is 52.66 hours and continuing to trend upwards. These time benefits are associated with better use of existing capacity in the overhead stream, and technology to 
reduce surface delay. Flights are able to successfully achieve an earlier CTOT with the IADS tools and the additional downstream effects of reducing surface congestion are also of significant benefit to operations. IADS overhead stream capabilities will be expanded in Phase 2 with electronic negotiation becoming available in Atlanta Center.

TABLE II. OVERHEAD STREAM INSERTION RENEGOTIATION BENEFITS

\begin{tabular}{|l|l|}
\hline \multicolumn{2}{|c|}{ Renegotiation Savings Data } \\
\hline $\begin{array}{l}\text { Total Flights Renogiated for an } \\
\text { Earlier APREQ Time }\end{array}$ & 386 \\
\hline $\begin{array}{l}\text { Average Delay Savings per Re- } \\
\text { negotiation }\end{array}$ & $8.19 \mathrm{~min}$ \\
\hline Total Delay Savings & $3159.87 \mathrm{~min}$ \\
\hline Total Delay Savings in Hours & $52.66 \mathrm{hr}$ \\
\hline Estimated Monetized Savings & $\$ 197,649.66$ \\
\hline
\end{tabular}

\section{Collaborative Surface Metering - Operational Data and Benefits}

Collaborative surface metering commenced on Nov 29, 2017 only during Bank 2 and is being consistently used in CLT across all runway configurations and meteorological conditions. On Feb 19, 2018 surface metering was expanded to Bank 3. The process of implementing surface metering has continued to be a collaborative process with metering target parameters and thresholds agreed upon between the CLT Tower TMCs and the ramp manager in the AAL Control Center. Metering parameters and the tactical scheduler algorithm have been continually calibrated/upgraded through the Phase 1 Baseline field demonstration. Metering data analysis has continued since the start of surface metering. This, in conjunction with consistent communication with users across the Tower and ramp, enabled the effective calibration of surface metering to ensure delay propagation occurred as expected and benefits were optimized. Given the variance in day to day operations in terms of runway utilization, number of controlled flights, density of the bank, and changes in overlap in departures and arrivals, detailed analysis is required.

Initial analysis indicates that of the banks metered up to May 2018, on average 13.8 flights were held for surface metering for an average gate hold of 5.6 minutes. In addition to these operational data, analysis shows reductions in excess AMA taxi out time and savings in fuel/emissions compared to pre-metering operations. Fig. 8. illustrates the average gate hold per day for flights subject to surface metering and the associated fuel burn savings as a result of the flights waiting at the gate rather than in queue at the runway. These initial fuel savings are based on the assumption that holding at the gate due to the IADS system advisories will result in one-to-one reduction in taxi-out time. The fuel burn calculation, similar to that above, is based on a standard calculation that utilizes the time savings and an assumption of an all-engine taxi at idle thrust under standard atmospheric conditions with estimates based on data from the ICAO Databank mapped to a given aircraft type. [25-27]

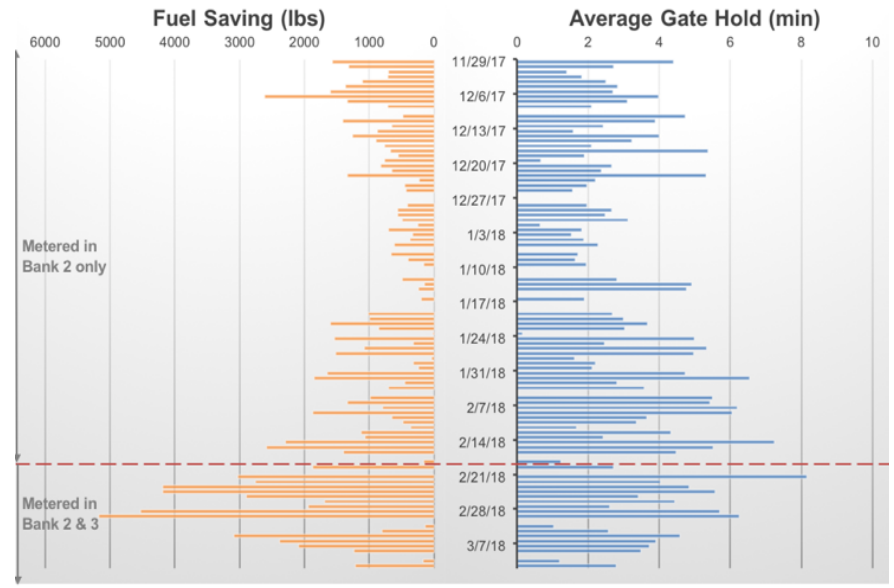

Fig. 8. Average gate hold values and associated fuel burn saving estimates during surface metering in the Phase 1 Baseline IADS Demonstration.

Early analysis of taxi times was also completed to understand the implications of surface metering. This analysis has shown that excess taxi time, or any taxi time greater than unobstructed trajectories of aircraft on the surface as computed by the surface model, has decreased in the AMA with the introduction of surface metering. As referenced in Section II.B. the use of excess taxi time enables the assessment of taxi time reduction without the geometry of the airport impacting taxi time metrics. Fig. 9. graphically shows the reduction in excess taxi time when comparing data in the AMA in North Flow Configuration prior to the implementation of surface metering (pre-metering) to after (post-metering). There is an average of 1.71 min reduced in AMA excess taxi time between pre and post metering. The shift of the blue curve (post metering) to the left of the red curve (pre metering) indicates the smaller amount of excess taxi time as well as smaller distribution, as there is less variance in the data once metering was introduced into the Phase 1 Field Demonstration.

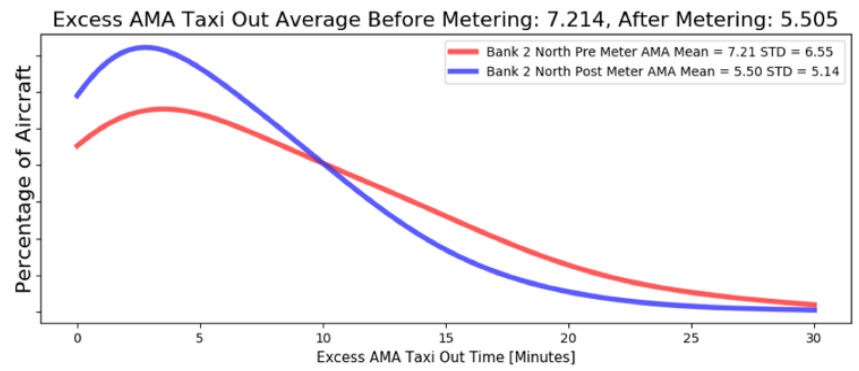

Fig. 9. Excess taxi time in the AMA pre and post metering.

In addition to reduction in excess taxi time, initial analysis indicates that there is no detrimental impact to downstream arrival times for flights that were subject to surface metering. Overall, considerable benefits as a result of surface metering have been realized since its implementation. From the end of November 2017 to May 2018, approximately 173,801 lbs. of fuel has been saved as a result of the short amount of hold at the gate due to surface metering advisories. Along with fuel burn savings as a result of shifting delay back from the runway queue to the gate, there have also been emissions savings associated with this capability. Approximately 243 metric tons of $\mathrm{CO} 2$ have been saved with the implementation of surface metering. 
Fig. 10. shows a bar chart illustrating the number of daily metric tons saved over time from November 28, 2017 to May 2018. The bar graph in Fig. 10 also demonstrates the multiplying benefits that are achieved with the commencement of surface metering in Bank 3 in February of 2018. As the surface metering is expanded to additional banks, more flights are subject to surface metering and additional delay is passed back from the runway to the gate resulting in greater fuel burn savings as well as emissions savings. Utilizing an Environmental Protection Agency formula, the metric tons of emissions savings can be also stated as equivalent to planting 6,226 urban trees. The assumptions and equation for tree growth were based on a Department of Energy formula and incorporate the amount of carbon dioxide that would be ingested across the average life span of a tree living in an urban area. [28]

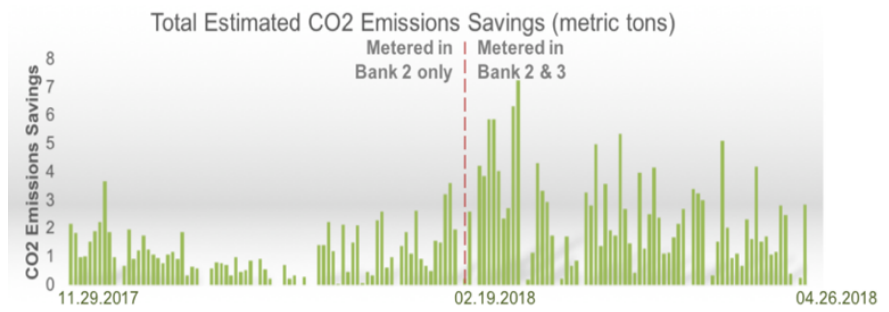

Fig. 10. Total Estimated Carbon Dioxide Emissions Saings in metric tons during collaborative suface metering.

Along with initial benefits data, several key insights regarding the manner in which the tactical scheduling algorithm operates as well as key lessons learned will be transferred to the FAA as part of the technical transfer process. One key insight includes the need to front load a surface metered bank for maximum benefit for both departure and arrival flows. By front loading a bank, the tactical scheduling algorithm assesses both the capacity imbalance as well as the current queue at the runway to ensure that flights taxi to the queue as needed at the start of bank. Otherwise, flights may be slow to be released from the gate, which has potential side effects including impact on departure metering procedures, delayed interaction of departure and arrival flights resulting in increased gate conflicts, and an overall negative impact on performance.

\section{CONCLUSION}

This paper presented Phase 1 initial benefits data of the baseline Integrated Arrival, Departure, and Surface technology demonstration at CLT as part of the ATD-2 project. The baseline IADS system enables common situational awareness across an airport's surface for both TMCs and ramp managers along with data and associated user interfaces to inform users about capacity, predictability, and efficiency of operations as a whole. This paper described the functions of the baseline IADS system along with initial benefits data associated with operational use of data exchange and integration, overhead stream insertion, and collaborative surface metering.

The Phase 1 Baseline IADS field demonstration commenced on September 28, 2017 and an analysis of the initial impact has indicated benefits as a result of use of the three capabilities outlined in this paper. Through a shared view of the airport surface, predicted demand of capacity, as well as shared information of TMIs, both FAA TMCs as well as airline ramp controllers experienced a reduction in the number of phone calls based on anecdotal references and gained a shared situational awareness of airport operations. CLT and Washington Center commenced overhead stream insertion electronically on November 1, 2017 and have demonstrated continuous use of this capability $(85 \%$ of all flights have been electronically negotiated), which provides a single view of overhead stream slots as well as the predicted take off time for a departure based on up-to-date airport surface operations. This capability has enabled greater predictability of aircraft entering the overhead stream as well as fuel burn savings through shared information of APREQ times, allowing for flights to remain at the gate if feasible. In addition, with electronic negotiation, TMCs have greater visibility into earlier slots that may be available and have used the capability to renegotiate flights for earlier APREQ times resulting in NAS wide delay savings on the order of 52.66 $\mathrm{hr}$. Furthermore, collaborative surface metering was initiated on November 28, 2018 and has been utilized across two banks at CLT resulting in 173,801 lbs. of fuel savings and 243 metric tons of $\mathrm{CO} 2$ savings by transferring delay from the runway queue back to the gate through small hold advisories. These initial metrics represent data up to May of 2018 and a full accounting of benefits metrics and data for Phase 1 baseline operations is continuing. Additional analysis demonstrating the performance of surface metering in regards to on time performance is also underway utilizing the FAA Aviation System Performance Metrics (ASPM) Database. Initial results are positive and do not show degradation in on time performance.

Continued analysis is essential to ensure effectiveness of collaborative surface metering. For example, as EOBT accuracy continues to improve, the IADS system also benefits from ramp controller input to indicate the actual flight pushback, which then inform surface metering start and end times. Using this actual demand, based on ramp controller input, metering initialization is much more predictable in terms of metering performance and generally leads to such benefits as more consistent taxi out times.

The Phase 1 baseline IADS field demonstration continues in CLT and in September of 2018 the demonstration will extend into the Phase 2 fused IADS demonstration. The Phase 2 IADS system will expand electronic overhead stream insertion into Atlanta Center and will enable increased predictability of flights in both Washington and Atlanta Centers. Collaborative surface metering will also be extended beyond the tactical realm and into strategic surface metering by enabling surface metering procedures to be set further out in time. This move into strategic surface metering will allow for assessment of the FAA's Surface CDM Concept of Operations and the TFDM Program. Furthermore, data exchange and integration continue in agile fashion with continuous additions based on feedback from operational users across CLT Tower and TRACON as well as AAL ramp operators. Through Phase 2, the IADS system will move beyond the baseline capabilities outlined in this paper and operational as well as benefits metrics will continue to be assessed throughout the field demonstration. 


\section{ACKNOWLEDGMENT}

The authors would like to acknowledge the operational personnel at CLT: ATC controllers, Traffic Management Coordinators (TMCs), AAL ramp controllers, and personnel from the National Air Traffic Controllers Association (NATCA), who have provided significant feedback to the development of the IADS system as well as enabled deployment of the system to operational locations. In addition, we would like to thank our FAA and AAL partners for their input and feedback in this ongoing process. The development of the ATD2 software was facilitated by Mosaic ATM. This research and development would not have been possible without the leadership and guidance of NASA Ames Aviation System Division management along with Project and Subproject management of ATD-2.

\section{REFERENCES}

[1] FAA, "NextGen Mid-Term Concept of Operations for the National Airspace System," version 2.1, September 2010.

[2] RTCA, NextGen Integration Working Group Rolling Plan - Final Report, June 2016.

[3] FAA Air Traffic Organization Surface Operations Office, "U.S. Airport Surface Collaborative Decision Making (CDM) Concept of Operations (ConOps) in the Near-Term", June 2012.

[4] Terminal Flight Data Manager (TFDM) Program Office, TFDM Core for ATCTs Concept of Operations, ConOps-PMO-02-TFDM-13-001, Rev 2.1, Nov 2013.

[5] Liu, Y., Hansen, M., Wang, Z., Gupta, G., and Malik, W., "Predictability in Airport Surface Operation Management," 2013 AIAA Aviation Technology, Integration, and Operations Conference, Los Angeles, CA, 12-14 Aug. 2013.

[6] Gupta, G., Malik, W., Tobias, L., Jung, Y., Hoang, T., and Hayashi, M., "Performance Evaluation of Individual Aircraft Based Advisory Concept for Surface Management," 10th USA/Europe ATM R\&D Seminar (ATM2013), Chicago, Illinois, 10-13 June 2013.

[7] Hayashi, M., Hoang, T., Jung, Y., Gupta, G., Malik, W., Dulchinos, V., "Usability Evaluation of the Spot and Runway Departure Advisor (SARDA) Concept in a Dallas/Fort Worth Airport Tower Simulation," 10th USA/Europe ATM R\&D Seminar (ATM2013), Chicago, Illinois, 10-13 June 2013

[8] Windhorst, R.D., "Towards a Fast-time Simulation Analysis of Benefits of the Spot and Runway Departure Advisor," AIAA-2012-4975, AIAA Guidance, Navigation, and Control (GNC) Conference, Minneapolis, MN, 13-16 Aug. 2012.

[9] Hoang, T., Jung, Y., Holbrook, J., and Malik, W., "Tower Controllers' Assessment of the Spot and Runway Departure Advisor (SARDA) Concept," 9th USA/Europe ATM R\&D Seminar (ATM2011), Berlin, Germany, 14-17 June 2011.

[10] Jung, Y., Hoang, T., Montoya, J., Gupta, G., Malik, W., Tobias, L., Wang, $H$. "Performance evaluation of a surface traffic management tool for Dallas/Fort Worth international airport," 9th USA/Europe Air Traffic Management R\&D Seminar, Berlin, Germany, June 14-17, 2011.

[11] Jung, Y. C., Hoang, T., Montoya, J., Gupta, G., Malik, W., and Tobias, L., "A Concept and Implementation of Optimized Operations of Airport Surface Traffic," 10th AIAA Aviation Technology, Integration, and Operations (ATIO) Conference, Fort Worth, TX, 13-15 Sep. 2010.

[12] Gupta, G., Malik, W., Jung, Y.C. "Effect of uncertainty on deterministic runway scheduling," 11th AIAA's Aircraft Technology, Integration, and Operations (ATIO), Virginia Beach, VA, September 20-22, 2011.
[13] Engelland, S.A. and Capps, A., "Trajectory-Based Takeoff Time Predictions Applied to Tactical Departure Scheduling: Concept Description, System Design, and Initial Observations," AIAA-20116875, 11th AIAA Aviation Technology, Integration, and Operations (ATIO) Conference, Virginia Beach, VA, 20-22 Sep. 2011.

[14] Capps, A. and Engelland, S.A., "Characterization of Tactical Departure Scheduling in the National Airspace System," AIAA-2011-6835, 11th AIAA Aviation Technology, Integration, and Operations (ATIO) Conference, Virginia Beach, VA, 20-22 Sep. 2011.

[15] Engelland, S.A., Capps, A., and Day, K., "Precision Departure Release Capability (PDRC) Concept of Operations," NASA/TM-2013-216534, June 2013.

[16] Engelland, S.A., Capps, A., Day, K., Robinson, C., and Null, J.R., "Precision Departure Release Capability (PDRC) Technology Description," NASA/TM-2013-216531, June 2013.

[17] Engelland, S.A., Capps, A., Day, K., Kistler, M., Gaither, F., and Juro, G., "Precision Departure Release Capability (PDRC) Final Report," NASA/TM-2013-216533, June 2013.

[18] Capps, A., Day, K., Walenciak, E., and Engelland, S.A., "Impact of Departure Prediction Uncertainty on Tactical Departure Scheduling System Performance," AIAA-2012-5674, 12th AIAA Aviation Technology, Integration, and Operations (ATIO) Conference, Indianapolis, IN, 17-19 Sep. 2012.

[19] Kistler, M., Capps, A., and Engelland, S., "Characterization of Nationwide TRACON Departure Operations," 2014 AIAA Aviation Technology, Integration, and Operations Conference, Atlanta, GA, 16-20 June 2014.

[20] Capps, A., Kistler, M., and Engelland, S., "Design Characteristics of a Terminal Departure Scheduler," 2014 AIAA Aviation Technology, Integration, and Operations Conference, Atlanta, GA, 16-20 June 2014.

[21] Jung, Y., Engelland, S., Capps, A., Coppenbarger, R., Hooey, B., Sharma, S., Stevens, L., Verma, S., Lohr, G., Chevalley, E., Dulchinos, V., Malik, W., and Morgan Ruszkowski, L., "Airspace Technology Demonstration 2 (ATD-2) Phase 1 Concept of Use (ConUse), NASA/TM-2018-219770," 28 Feb. 2018

[22] Ging, A., Engelland, S., Capps, A., Eshow, M., Jung, Y., Sharma, S., Talebi, E., Downs, M., Freedman, C., Ngo, T., Sielski, H., Wang, E., Burke, J., Gorman, S., Phipps, B., and Morgan Ruszkowski, L., "Airspace Technology Demonstration 2 (ATD-2) Technology Description Document (TDD)," NASA/TM-2018-219767, 31 March 2018.

[23] L. Stevens, T. Callentine, \& R. Staudenmeier, "Evolution of Electronic Approval Request Procedures at Charlotte Douglas International Airport". 37th DASC, 2018, in press.

[24] "Vision for Trajectory Based Operations", FAA, Version 2.0, Sept 2017.

[25] Jung, Y., "Fuel Consumption and Emissions from Airport Taxi Operations," NASA Green Aviation Summit, 2010.

[26] ICAO Engine Emissions Databank," http://www.caa.co.uk/default.aspx?catid=702\&pagetype $=90$, [Retrieved December 2010].

[27] Collins, B., "Estimation of Aircraft Fuel Consumption," Journal of Aircraft, Vol. 19, No. 11, Nov. 1982, pp. 969-975.

[28] U.S. DOE (1998). "Method for Calculating Carbon Sequestration by Trees in Urban and Suburban Settings," Voluntary Reporting of Greenhouse Gases, U.S. Department of Engergy, Energy Information Adminstration. 